\title{
Doctors, unethical treatments, and turning a blind eye
}

\author{
Questions after the selling of an unethical treatment for AIDS
}

The recent case of a doctor and veterinary surgeon selling for huge sums an untested "cure" for AIDS and cancer raises many issues, some of which are discussed on $p 1171$ by Duncan Campbell, the investigative journalist who brought the case to public attention. ${ }^{1} \mathrm{He}$ wants to know why doctors who knew about the case were so slow to act. The General Medical Council's rules on doctors not disparaging other doctors may, he argues, act directly against the public interest, although the council does require doctors to take action when they think their colleagues may be guilty of serious professional misconduct. Also raised are the issues of doctors practising in private with almost no ethical constraint and the uncritical reporting of doubtful treatments by the media.

Dr James Sharp, a haematologist, and Abdul Jabar Sultan, a veterinarian, developed their immunotherapy at King's College Hospital, London. Their "adoptive immunotherapy" consisted of injecting patients with lymphokine stimulated killer T cells. Sharp and Sultan were given limited ethical approval to treat patients terminally ill with leukaemia. Sharp left King's in 1986 to go into private practice, and Sultan was told to leave the hospital in 1987 after his head of department and two experts in immunology reviewed his work and found it worthless. He had proposed trying the treatment on patients with AIDS but was warned that on theoretical grounds the treatment might accelerate the disease.

In late 1986 Sharp set up a private company-Brownings Clinical Pathology Services - which among other activities offered "adoptive immunotherapy," and in 1987 the company employed Sultan. Later that year the private London Bridge Hospital leased to the company laboratories and space for the treatment. Sharp then treated two patients with severe HIV infection without having completed adequate tests of safety. The two patients came from the NHS, and the consultant who looked after them said that they were neither worse nor better after the experiment. But in December 1987 an article appeared in the Daily Express written by a friend of Sharp's reporting his claim of "significant improvement" in the two "guinea pigs." In May 1988 an article appeared in the Daily Telegraph in which after no further research Sharp claimed that patients with AIDS could "at least be stabilised and possibly cured." An article was published in New Scientist, but "scientific" papers submitted to Nature and the $B M \mathcal{F}$ were rejected. A half page grant application to the Medical Research Council was turned down.
After the Daily Telegraph article patients with AIDS came forward and were charged several thousand pounds for treatment. In November 1988 Sultan presented his results at a meeting of the British Society of Immunology: one consultant said that he had "never seen anything so appalling," and another described it as "the most scientifically unfounded presentation I'd ever heard." Sultan claimed to have produced "significant long lasting clinical improvement" in three patients with AIDS, but two were already dead and one died six days later. Altogether more than 30 patients with AIDS, cancer, or leukaemia were charged thousands of pounds and given the treatment at the London Bridge Hospital.

Campbell brought the affair to public attention by attending Sharp at the hospital together with a healthy accomplice who pretended to have AIDS. The whole interview was secretly taped for the BBC television programme Watchdog. Sharp prescribed a $£ 10000$ course of immunotherapy after six minutes, taking a history in a consultation in which he did not examine the "patient" but told him that "we're looking for indefinite survival." The "patient" was told to stop his conventional drugs against AIDS. Sharp and Sultan have now left the London Bridge Hospital.

The selling of quack cures by doctors is, sadly, nothing new, but this is the most flagrant case for years. Why, Campbell asks, didn't one of the many doctors who knew something of what Sharp and Sultan were up to take some action? One impediment may be the GMC's statement that "it is improper for a doctor to disparage, whether directly or by implication, the professional skill, knowledge or qualifications or services of any other doctor... . such disparagement may raise a question of serious professional misconduct."' To Campbell this looks like straight professional protectionism, but the "blue book" also says that "a doctor has a duty, where the circumstances so warrant, to inform an appropriate body about a professional colleague whose behaviour may have raised a question of serious professional misconduct."”

The truth is that it probably does not matter too much what the "blue book" says. Doctors are stopped from shopping their colleagues not so much by the letter of the law but more by a deep distaste for doing so. The same distaste operates in reporting colleagues who are sick or incompetent. A rationalisation for not doing so is the difficulty of accumulating evidence, and in a case like this by the knowledge that 
scientific advances often depend on the apparently unconventional. If the doctor contacts the GMC it will immediately ask for evidence. The preliminary screener of the council has to consider the quality of the evidence that will be adduced because if it is inadequate then the later committees will quickly dismiss the case. One objection people raise against the council is that it has no "police force," but the preliminary screener may ask the council's solicitors to investigate a case if it seems that serious professional misconduct may have occurred. This is naturally a limited investigation, and it is doubtful that the council could have coped with accumulating for itself the evidence that was needed in this case. It took an investigative journalist with the resources of a television programme behind him to gather the evidence, raising questions about the strength of the professional machinery and the unwisdom of being too quick to condemn all "trials by media." In the light of this case the GMC needs to consider hard whether it needs more investigative machinery.

Alternatively, doctors worried about the practices of Sharp and Sultan might have presented their worries to the authorities of the London Bridge Hospital. This naturally would have been an awkward task, but there would also have been worries about how far the hospital would have been able to take the protestations. The hospital had no ethical committee to approve the experiments of Sharp and Sultan, and its medical advisory committee had simply accepted
Sharp's claims to have ethical and scientific backing for what he was doing. Campbell raises questions about the dangers inherent in the expansion of private practice, and these are questions that also worry the GMC. To a large extent the council depends on the NHS machinery for investigating complaints, and because it has no power over specialist registration the council cannot stop doctors in private practice from claiming skills that they do not have. Unscrupulous doctors may prosper within the NHS, but they can prosper much more easily in private practice - as unhappy episodes with slimming clinics, cosmetic surgery, and selling kidneys illustrate. The government is acting this week to outlaw the sale of kidneys, providing another example of failure of professional safeguards and necessity for government action. The ethical dangers in the expansion of private practice have to be recognised and countered.

Finally, as well as the ethics of doctors the practices of the media need to be questioned. The Daily Express and the Daily Telegraph have reported this dubious treatment, yet they have not publicised the treatment's downfall. They should.

RICHARD SMITH

Assistant editor, $B M \mathcal{F}$

1 Campbell D. Sharp practice. New Statesman and Society 1989 April 7:10-4

2 General Medical Council. Professional conduct and discipline: fitness to practice. London: GMC, 1987:17

\section{Visual disability and the elderly}

\section{Time for general practitioners to begin preventive screening}

The proportion of the population over 65 is increasing, and more of these people are having to look after themselves. To do so they must retain their faculties, and none is more important than sight.

Surveys of eye disease in elderly hospital outpatients show that the most common referrals are for cataracts $(25 \%)$, senile macular degeneration (12\%), and glaucoma (14\%).' Although the referral to hospital comes from the general practitioner the diagnosis has usually been suggested by an optician. ${ }^{23}$ Most referrals result from symptomatic disease and so do not reflect the true prevalence of these diseases in the community. ${ }^{1}$ Population surveys provide better estimates. ${ }^{45}$ These have found cataract or macular disease sufficient to reduce visual acuity slightly $(<6 / 9)$ in nearly half of the over 75 s and glaucoma in about $7 \%$. Though high prevalence does not mean inevitable "blindness," a recent study of patients attending a geriatric day care centre found that one third had unrecognised severe visual loss. ${ }^{6}$ These figures suggest a serious underdiagnosis of (commonly asymptomatic) treatable eye disease in elderly patients.

What level of preventive eye care, therefore, should elderly patients be offered? Until now screening for glaucoma has been mainly restricted to patients with a family history of the disease. All patients considered to be at risk should, however, be screened every two years. In addition, because the incidence of open angle glaucoma has been estimated as $0.5 \%$ in five years for 65 year olds and $1 \cdot 1 \%$ in five years for 75 year olds $^{7}$ two yearly screening should be offered to this population too.

Setting up a screening programme for the elderly would be expensive. A similar programme in the United States was costed at $\$ 100-300 \mathrm{~m}$ for the first year, rising with rescreening of the same patients every two years. ${ }^{8}$ The chances of additional funding for a similar programme in the United Kingdom are not high, and screening would probably have to rely on existing funds. At present the government pays for screening of the families of glaucoma patients, and it may provide them with free sight tests by opticians in the future. In view of the prevalence of glaucoma in the elderly perhaps screening should also be extended to them.

Who should screen the elderly? At present, almost by default, this is left to ophthalmic opticians. General practitioners refer patients with symptoms and identify those with disease of the outer eye. ${ }^{3}$ Diagnosis of diseases in the posterior segment will be made only by ophthalmic opticians until medical students are taught adequate ophthalmoscopy. General practitioners' present degree of proficiency is unfortunate; they are far better placed to examine the individual patients "at risk," and tonometry and ophthalmoscopy take little time for experienced staff.

Most patients referred with asymptomatic early cataract, macular change, or ocular hypertension without glaucoma will require only intermittent observation. As they would far outnumber patients needing treatment any increases in their referral rate would rapidly swamp ophthalmic clinics. As ophthalmic services in the United Kingdom are fully occupied with patients needing treatment this extra burden could be taken on only with a large increase in staffing and facilities.

Cost is another consideration. Hospital visits cost about $£ 30$ each, sight tests about $£ 10$, and a visit to a general practitioner possibly even less. After an initial hospital referral it would be considerably cheaper for opticians or general practitioners to follow the patients up. ${ }^{3}$ 